Нечаев Алексей Игоревич

аспирант кафедры «Финансовые рынки» Российского экономического университета имени Г.В. Плеханова

\section{РАЗВИТИЕ ВЗАИМОДЕЙСТВИЯ БАНКОВСКИХ УЧРЕЖДЕНИЙ И СТРАХОВЫХ КОМПАНИЙ В РОССИИ}

\begin{abstract}
Аннотация:
Смежный рынок банковских и страховых услуг является одним из самых быстроразвивающихся секторов современной России. Предметом исследования выступает область применения смежных финансовых продуктов банковской и страховой области. Цель исследования - выявление обстоятельств, способствующих развитию смежного рынка предоставления финансовых услуг населению. В работе произведено аналитическое исследование, которое базируется на определении экономических и социальных факторов влияния на рынок банкострахования. Использован метод выработки основополагающих причин корреляции взаимодействия между банковскими учреждениями и страховыми компаниями. Развитие банковских учреждений и страховых компаний в России напрямую зависит от текущего состояния экономического развития. Ключевым направлением создания и стандартизации внутренних процессов на смежном рынке банкострахования является учреждение отдельного государственного органа, который будет способствовать развитию процессов управления рисками обоих сегментов. Данный орган также может способствовать развитию рынка долгосрочного финансирования в Poccuu.
\end{abstract}

Ключевые слова:

банковское дело, страховой рынок, страхование, банки, институционализация рынка, кредитование, рынок банкострахования, финансы.
Nechaev Aleksey Igorevich

PhD student Financial Markets Department, Plekhanov Russian University of Economics

\section{INTERACTION BETWEEN BANKING AND INSURANCE COMPANIES IN RUSSIA: DEVELOPMENT PROSPECTS}

Summary:

Development of the contiguous banking and insurance services is one of the fastest growing trends today in Russia. The research focuses on the scope of contiguous financial products of both banking and insurance fields. The purpose of the study is to identify the circumstances conducive to the development of adjacent market providing financial services to the population. The research methodology is an analytical study based on the economic and social factors, which influence the bank insurance market. The author reveals the fundamental reasons for the correlation between banking and insurance companies. Nowadays, the development of common banking and insurance services highly depends on the current state of economic development. The key area of creation and standardization of internal processes on the adjacent banking and insurance markets is the establishment of a separate government agency that will promote the development of risk management processes for both segments. This body can contribute to the development of the long-term financing market in Russia as well.

Keywords:

banking sector, insurance market, insurance, banks, market institutionalization, crediting, bank insurance market, finances.

В 2016 г. банковский сектор России показал хорошие ключевые показатели прибыльности, несмотря на то что было зафиксировано небольшое снижение банковских активов на $4 \%$ почти до 80 трлн р. По данным Банка России, только за первые девять месяцев 2016 г. банковский сектор России получил совокупную прибыль в размере 635 млрд р., что более чем в четыре раза превышает показатель 2014 г. - 127 млрд р. Несмотря на неплохую динамику, показатель прибыльности является далеко не усредненным по отрасли. Так, более 376 млрд р. из общей совокупной прибыли пришлось на долю ПАО Сбербанк. Розничное кредитование фризических лиц в этот период увеличилось на 0,5 \%, тогда как объемы выданных кредитов нефинансовому сектору сократились почти на 7 \% [1].

Также за 2016 г. вырос показатель просроченной задолженности, а именно:

- по кредитам нефинансовым организациям - с 2,075 до 2,122 трлн р. (в долях от общей массы - с 6,3 до 6,9\%);

- в потребительском кредитовании - с 863,9 до 916,2 млрд р. (в общей массе - на 8,5 \%).

Депозитарные вклады населения по итогам 2016 г. выросли на 0,5 \% до 23,218 трлн р., в то время как объем средств и депозитов на счетах юридических лиц снизился на 10,2 \% до 24,3 трлн р. [2].

В целом банковский сектор должен подвергнуться значительным переменам, чтобы преодолеть накопившиеся на рынке банковских услуг России проблемы и создать пространство для устойчивого и стабильного роста. 


\section{Страховой рынок России}

По итогам 2016 г. деятельность страховых компаний может быть охарактеризована как успешная. Общий объем страховых премий увеличился на 15,2 \%. Наряду с этим показателем впервые с 2011 г. показатель объема выплат продемонстрировал отрицательную динамику.

Соотношение темпов роста премий к выплатам также продолжает демонстрировать положительную динамику. Несмотря на то что в предыдущие годы темпы роста премий значительно отставали от темпов роста выплат (пик был достигнут в 2015 г.), в 2016 г. ситуация кардинально изменилась и темпы выплат продемонстрировали отрицательную динамику [3]. Следует также отметить, что ситуация вокруг этих показателей показывает хорошую динамику лишь в некоторых компаниях, ввиду того что такой рост страховых премий является в основном результатом увеличения числа клиентов, кто пользуется страхованием жизни.

Таблица 1 - Основные показатели страхового рынка России в период с 2010 по 2016 г. [4]

\begin{tabular}{|c|c|c|c|c|c|}
\hline Год & $\begin{array}{c}\text { Страховые } \\
\text { премии, млрд р. }\end{array}$ & $\begin{array}{c}\text { Темпы роста } \\
\text { премий, \% }\end{array}$ & $\begin{array}{c}\text { Страховые } \\
\text { выплаты, млрд р. }\end{array}$ & $\begin{array}{c}\text { Темпы изменения } \\
\text { выплат, \% }\end{array}$ & $\begin{array}{c}\text { Коэффициент } \\
\text { выплат, \% }\end{array}$ \\
\hline 2010 & 555,82 & 4,2 & 295,98 & 3,81 & 53,26 \\
\hline 2011 & 665,02 & 19,66 & 303,77 & 2,64 & 45,69 \\
\hline 2012 & 809,05 & 21,67 & 369,45 & 21,63 & 45,67 \\
\hline 2013 & 904,87 & 11,2 & 420,78 & 12,91 & 46,51 \\
\hline 2014 & 987,78 & 8,51 & 472,28 & 11,45 & 47,82 \\
\hline 2015 & 1023,83 & 3,34 & 509,23 & 7,12 & 49,74 \\
\hline 2016 & 1180,64 & 15,31 & 505,8 & $-0,68$ & 42,85 \\
\hline
\end{tabular}

Изменение темпов роста страховых премий в области страхования жизни оказалось наиболее значительным за период с 2010 г. и составило 60,6 \% в 2013 г., 28 \% в 2014 г., 19,2 \% в 2015 г. и 66,4 \% в 2016 г. Основным драйвером такого увеличения оказались продукты инвестиционного страхования. В основном это произошло благодаря низким ставкам по депозитам. На рисунке 1 показаны темпы изменения страховых премий и выплат. На графике можно выделить снижающуюся динамику в периоде замедления экономического роста в 2014 г. В 2015 г. после прохождения критической фразы кризиса темпы прироста премий значительно увеличились.

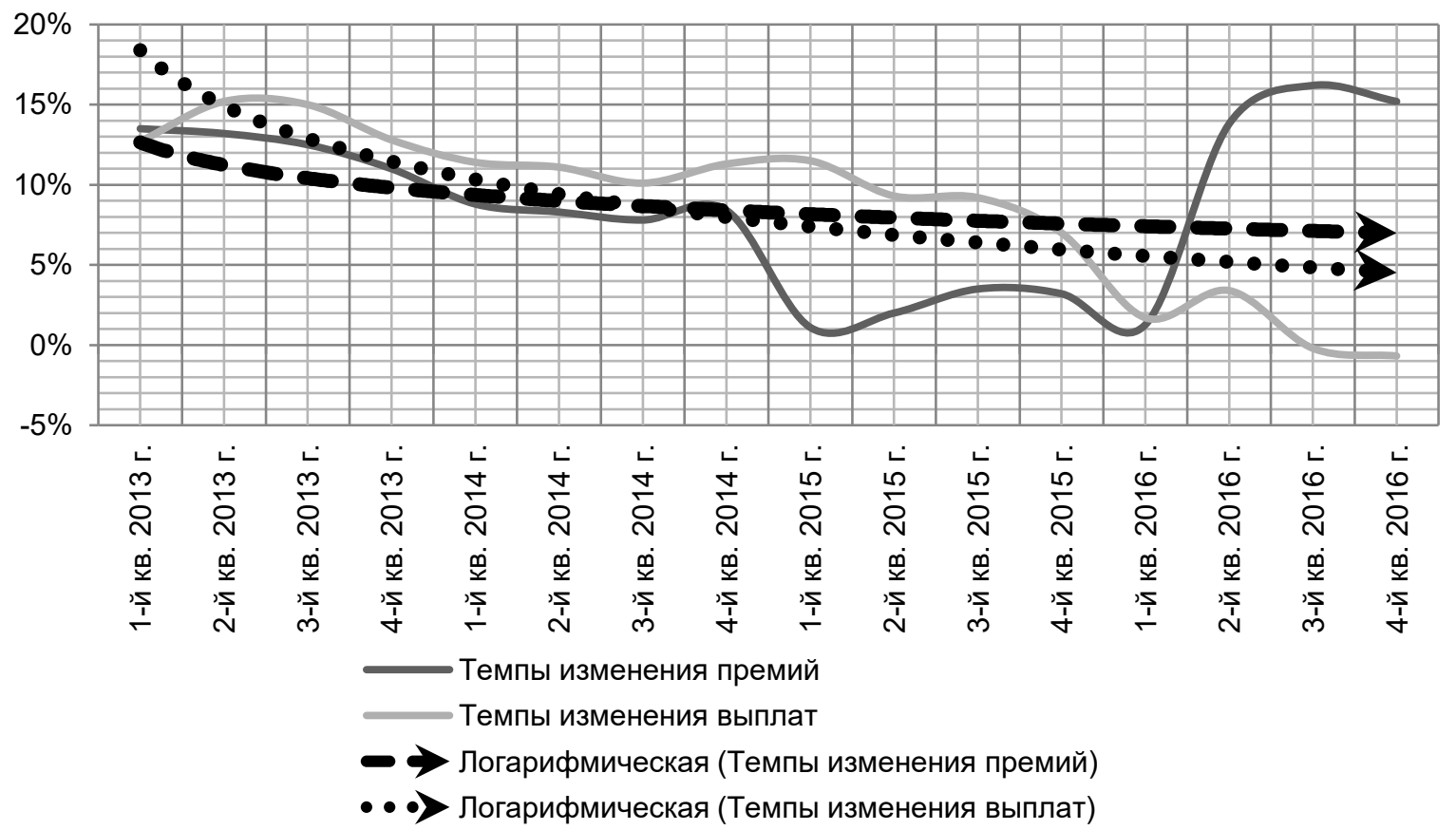

Примечание. Курсивными линиями продемонстрирована динамика развития изменения.

\section{Рисунок 1 - Соотношение темпов корреляции страховых премий и страховых выплат [5]}

На данный момент в сегменте страхового рынка ведут свою деятельность 35 компаний, в 2016 г. их насчитывалось 38. Конкуренция между компаниями продолжает усиливаться и на протяжении уже долгого времени остается одной из самых высоких в сравнении с другими продуктами страхования. Динамика сокращения числа частных компаний в страховом сегменте говорит о стандартизации рынка страховых услуг и снижении конкуренции. Большие компании поглощают 
более мелких, в то время как территориальное расширение предложения услуг по регионам происходит низкими темпами. В таблице 2 приведены топ 10 страховых компаний России по состоянию на 2017 г.

Таблица 2 - Самые крупные страховые компании в России [6]

\begin{tabular}{|l|c|c|c|c|}
\hline Название страховой компании & Год основания & $\begin{array}{c}\text { Число } \\
\text { сотрудников }\end{array}$ & $\begin{array}{c}\text { Страховые премии, } \\
\text { млрд р. (год) }\end{array}$ & Сеть \\
\hline ПАО СК «Росгосстрах» & 1992 & 100000 & $149(2015)$ & 3900 \\
\hline АО «СОГАЗ» & 1993 & 6529 & $140(2015)$ & 273 \\
\hline СПАО «Ингосстрах» & 1947 & 6437 & $87(2016)$ & 300 \\
\hline СПАО «РЕСО-Гарантия» & 1991 & 20000 & $78(2015)$ & 800 \\
\hline «АльфаСтрахование & 1992 & 5500 & $63(2016)$ & 270 \\
\hline САО «ВСК» & 1992 & 6970 & $34(2012)$ & 764 \\
\hline Страховая компания «Согласие» & 1993 & 4500 & $34(2016)$ & 350 \\
\hline ООО СК «ВТБ Страхование» & 2000 & 550 & $62(2016)$ & 60 \\
\hline АО СК «Альянс» & 1991 & 4000 & $4(2016)$ & 70 \\
\hline АО «Страховая группа МСК» & 1993 & 3000 & $7(2015)$ & 155 \\
\hline
\end{tabular}

Примечание. Курсивом обозначены приблизительные показатели.

В последнее время начала формироваться устойчивая связь между финансовыми и страховыми компаниями. Пользуясь услугами банков, страховые организации имеют возможность эффективно управлять своими финансовыми активами, в то время как банки также могут пользоваться услугами по риск-менеджменту страховых компаний. Также банковские учреждения активно внедряют механизмы продажи страховых продуктов через свои филиалы. В последнее время ряд государственных банков стал активно предлагать программы страхования имущества и жизни, при этом выступая лишь посредником между клиентами и страховыми компаниями. Такая двусторонняя связь эффрективно удовлетворяет запросы всех сторон. На этом фроне также активно начали появляться смежные продукты и услуги, затрагивающие оба рынка. С момента становления рыночных отношений в России начались процессы слияния и поглощения, которые впоследствии привели к созданию финансовых союзов между банками и страховыми организациями. Сегодня существует несколько моделей такого развития. В таблице 3 приведены основные модели сотрудничества страховых компаний и банков.

Таблица 3 - Основные модели развития отношений между банковскими учреждениями и страховыми компаниями [7]

\begin{tabular}{|c|c|c|c|c|}
\hline Модель & Описание & $\begin{array}{l}\text { Сильные } \\
\text { стороны }\end{array}$ & $\begin{array}{l}\text { Слабые } \\
\text { стороны }\end{array}$ & $\begin{array}{c}\text { Страны массового } \\
\text { распространения }\end{array}$ \\
\hline $\begin{array}{l}\text { Соглашение о сотруд- } \\
\text { ничестве в распро- } \\
\text { странении } \\
\text { (Agreement on Coopera- } \\
\text { tion in the Dissemination) }\end{array}$ & $\begin{array}{l}\text { Банковские организа- } \\
\text { ции выступают в роли } \\
\text { посредника между } \\
\text { страховыми компани- } \\
\text { ями и их клиентами }\end{array}$ & $\begin{array}{l}\text { Низкие капи- } \\
\text { тальные вло- } \\
\text { жения, малые } \\
\text { временные } \\
\text { затраты }\end{array}$ & $\begin{array}{l}\text { Трудности, } \\
\text { связанные с } \\
\text { запусками но- } \\
\text { вых продуктов } \\
\text { и услуг }\end{array}$ & $\begin{array}{l}\text { Германия, США, } \\
\text { Южная Корея, Япо- } \\
\text { ния }\end{array}$ \\
\hline $\begin{array}{l}\text { Соглашение о дого- } \\
\text { ворном совместном } \\
\text { предприятии } \\
\text { (Contractual Joint Ven- } \\
\text { ture Agreement) }\end{array}$ & $\begin{array}{l}\text { Банковские и страхо- } \\
\text { вые организации со- } \\
\text { трудничают в преоб- } \\
\text { разовании продуктов и } \\
\text { услуг }\end{array}$ & $\begin{array}{l}\text { Обмен опы- } \\
\text { том и навы- } \\
\text { ками }\end{array}$ & $\begin{array}{l}\text { Некоторые за- } \\
\text { труднения в } \\
\text { процессах } \\
\text { управления }\end{array}$ & $\begin{array}{l}\text { Испания, Южная Ко- } \\
\text { рея, Португалия, } \\
\text { Италия }\end{array}$ \\
\hline $\begin{array}{l}\text { Интегрированные биз- } \\
\text { нес-группы } \\
\text { (Integrated Business } \\
\text { Groups) }\end{array}$ & $\begin{array}{l}\text { Создание нового сов- } \\
\text { местного учреждения }\end{array}$ & $\begin{array}{l}\text { Единая струк- } \\
\text { тура }\end{array}$ & $\begin{array}{l}\text { Значительные } \\
\text { капитальные } \\
\text { вложения }\end{array}$ & $\begin{array}{l}\text { Испания, } \text { Велико- } \\
\text { британия, Бельгия, } \\
\text { Ирландия, Франция }\end{array}$ \\
\hline
\end{tabular}

Развитие сотрудничества банков и страховых компаний происходит высокими темпами. Ввиду того что по условиям вступления Российской Федерации во Всемирную торговую организацию в 2019 г. страховой рынок России должен будет открыть свои границы для иностранных страховых компаний, развитие отечественного страхового рынка должно происходить быстрыми темпами. Взаимная работа страховых и банковских учреждений может способствовать существенному росту банкострахования. Главными направлениями могут быть: территориальное расширение предложения; приток новых клиентов; сегментация рынка и выявление новых моделей распределения услуг; возможность точечного таргетирования; увеличение рынка; снижение операционных издержек; снижение рисков.

Сотрудничество страховых компаний и банковских учреждений потенциально обладает рядом преимуществ для каждой из сторон (табл. 4). 
Таблица 4 - Выгоды от взаимного сотрудничества для банковских учреждений и страховых компаний

\begin{tabular}{|l|l|}
\hline \multicolumn{1}{|c|}{ Выгоды для банковских учреждений } & \multicolumn{1}{c|}{ Выгоды для страховых компаний } \\
\hline Увеличение прибыли & Снижение капитальных издержек \\
\hline Новая клиентская база & Новая клиентская база \\
\hline Более плотная работа с клиентами & Новые сегменты рынка \\
\hline Повышение качества обслуживания & Повышение качества обслуживания \\
\hline
\end{tabular}

\section{Развитие рынка банковского страхования}

В настоящее время финансовый сектор России переживает переходный период. С одной стороны, в экономике после кризиса в нефтегазовой отрасли начался процесс стабилизации, а с другой - доверие населения к финансовым учреждениям остается на низком уровне. С конца 1990-х гг. число фринансовых организаций в России стремительно уменьшалось. В 2017 г. процесс реорганизации начали два больших частных банка, входящих в топ 10 банков России. Многие эксперты отмечают высокий спрос Центрального банка России на регулирующее участие в банковском секторе. Переход двух больших частных банков под прямое влияние Банка России означает, что по состоянию на октябрь 2017 г. в первой десятке банковских учреждений по активам остаются только три частные структуры. Банковский сектор России имеет ряд трудностей, схожих со страховым рынком, а именно снижение конкуренции, территориальное таргетирование (предложение услуг не во всех регионах страны), низкие темпы развития, слабое регулирование, отсутствие долгосрочных программ.

Ввиду низких показателей доверия населения фринансовым компаниям остаются актуальными вопросы будущего развития как банков, так и страховых компаний. Для стабильных показателей роста данные секторы должны выработать долгосрочную стратегию развития финансовых продуктов, которая сможет выполнять следующие задачи: снижение издержек, приток капитала, увеличение территориального присутствия, развитие смежных фринансовых услуг [8].

Как было указано ранее, в последнее время рынок банкострахования постепенно набирает обороты в России [9]. В 2015 г. объемы данного рынка составили чуть более 210 млрд р. Динамика этого рынка показывает нулевой рост за последние два года. Основной причиной этого служит падение кредитного страхования. Ввиду того что после начала кризиса 2014 г. объемы страхования в России существенно сократились, что в целом сказалось на всей финансовой системе, отдельный показатель кредитного розничного страхования снизился более чем на 20 \%. Системе страхования пришлось искать кардинальные решения и переориентироваться на «некредитные» виды страхования. Объемы этого сегмента в 2015 г. выросли на 43 \%. Несмотря на все изменения, показатель объема страхования розничных кредиторов имеет большую долю во всем смежном рынке банкострахования и составляет чуть менее $50 \%$.

Другим существенным фрактором служит ужесточение регулирования банковского сектора, а именно Центральный банк России проводит политику снижения рисков при программах долгосрочного кредитования, в частности ипотечных программах. Создание модели разделения фринансовых рисков долгосрочного финансирования может стать существенным стимулом развития рынка банкострахования. Одним из приоритетных направлений развития рынка банкострахования является создание отдельного органа, который сможет наладить бизнес-процессы сотрудничества банковских учреждений и страховых компаний [10].

На рисунке 2 можно увидеть структуру рынка банкострахования по состоянию на 2017 г.

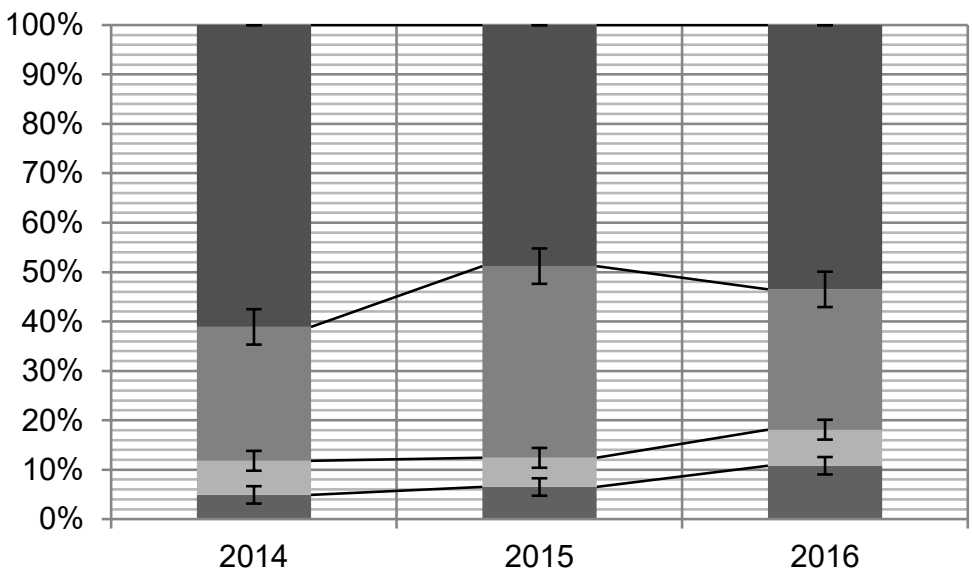

- Кредитное страхование клиентов банков

- Некредитное страхование клиентов банков

- Страхование юридических лиц в банковских учреждениях

- Страхование банковских рисков

Рисунок 2 - Динамика структуры рынка банковского страхования в России за 2014-2016 гr. [11] 
Как видно из графика, динамика развития отдельных сегментов на рынке банкострахования является разнонаправленной. Объемы страхования банковских рисков стабильно увеличивают свою долю в общей структуре активов, в то же время страхование клиентов банковских учреждений до сих пор имеет негативный тренд ввиду сильных финансовых потрясений на всем фринансовом рынке. На рисунке 3 показана динамика развития рынка банкострахования.

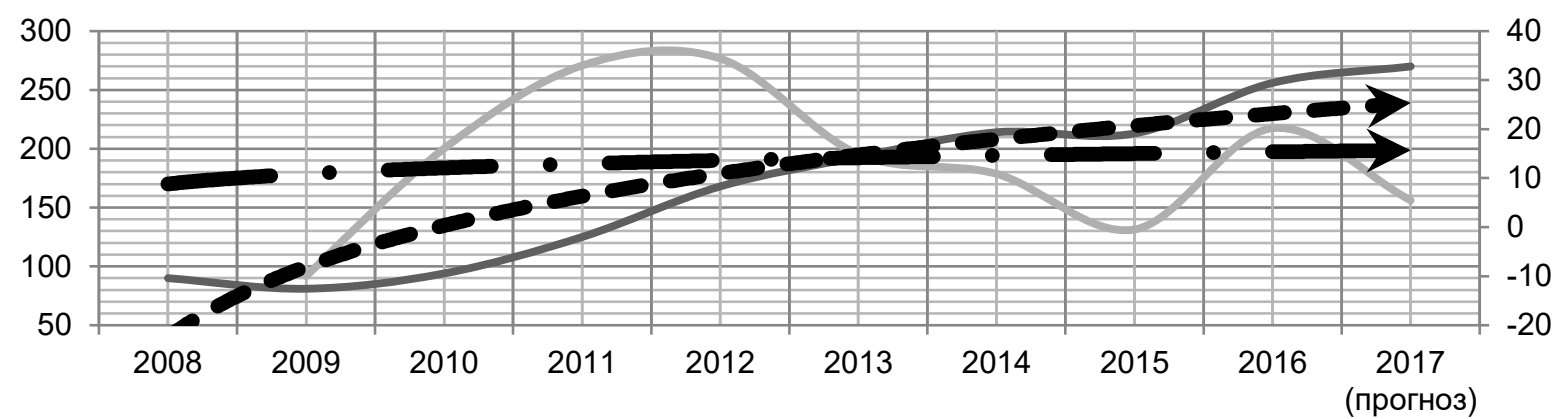

Примечание. Черная линия обозначает объемы рынка банковского страхования за период с 2008 по 2017 г., в млрд р. Серая линия показывает процентное соотношение изменения к предыдущему году, исчисляется по правой вспомогательной шкале, в \%.

\section{Рисунок 3 - Динамика развития рынка банковского страхования в России [12]}

По состоянию на период 2015-2016 гг. большая удельная доля рынка принадлежала первым десяти компаниям, что в совокупности составило более 70 \%. Объемы роста рынка банковского страхования в последнее время обусловлены увеличением некредитного страхования, аффинированного с банковскими учреждениями [13].

Современный этап развития банковского и страхового секторов характеризуется существенными изменениями, которые заключаются в следующем: развитие программ долгосрочного финансирования, разделение рисков между всеми участниками рынка, создание новых продуктов смежной отрасли банковского и страхового секторов, направленное таргетирование, территориальное расширение предложения услуг.

Рынок банковского страхования является относительно молодым в России. Развитие этого сегмента происходит довольно быстрыми темпами. Ввиду запрета прямого присутствия иностранных страховых компаний в России до 2019 г. по договорам ВТО в сегодняшних реалиях отечественные страховые компании имеют явные преимущества, а именно в части конкуренции. В рамках участия России во Всемирной торговой организации в конце 2019 г. будут открыты границы для прямых зарубежных инвестиций в страховой бизнес в России, в том числе большие зарубежные страховые компании смогут открывать собственные филиалы на территории РФ.

На сегодняшний момент развитие рынка банковского страхования находится в начале своего пути, его объемы составляют доли процента, что является очень низким показателем среди развитых и развивающихся стран. Основными направлениями развития смежных продуктов рынка банкострахования являются: диверсификация рисков долгосрочного кредитования, страхование жизни и имущества при программах кредитования, привлечение капитала, создание финансовых моделей сотрудничества, таргетирование клиентов, снижение издержек.

Одним из важных факторов, который может сильно стимулировать дальнейшее развитие данного рынка, является создание государственной структуры, основной целью которой будет регулирование взаимодействия банковских учреждений и страховых компаний. Ввиду сильного территориального различия многих субъектов России и серьезного разрыва в покупательской способности населения развитие сетей банковских учреждений и страховых компаний кардинально различается. Создание единого регулирующего реестра может активно способствовать слиянию филиалов и отдельных офисов, которые будут предоставлять как банковские, так и страховые услуги.

\section{Ссылки и примечания:}

1. Банковский сектор [Электронный ресурc]. URL: http://www.cbr.ru/analytics/?prtid=bnksyst (дата обращения: 20.01.2018); О развитии банковского сектора России [Электронный ресурc]. URL: http://www.webeconomy.ru/index. .php?page=cat\&cat=mcat\&mcat=217\&type=news\&p=6\&newsid=3425 (дата обращения: 20.01.2018).

2. По данным Центрального банка Российской Федерации.

3. Загирова Н.Р., Александрова Н.Г. Анализ страхового рынка РФ на период 2014-2016 гг. и перспективы его развития [Электронный ресурс] // Фундаментальные исследования. 2016. № 11, ч. 5. C. 1006-1010. URL: http://fundamentalresearch.ru/ru/article/view?id=41292 (дата обращения: 13.02.2018). 
4. Страховой рынок России в 2016 г. [Электронный ресурс] / Национальное рейтинговое aгентство. URL: http://www.ranational.ru/sites/default/files/analitic_article/Аналитический\%20обзор-\%20страховой\%20рынок\%20-2016.pdf (дата обращения: 20.01.2018).

5. Итоги 2016 г.: сумма страховых премий увеличилась более чем на 15 \% [Электронный pecypc]. URL: http://www.finmarket.ru/insurance/?nt=1\&id=4509019 (дата обращения: 20.01.2018) ; Крупнейшие страховые компании по итогам І полугодия 2017 г. [Электронный ресурс]. URL: http://riarating.ru/insurance_companies/20170929/630074092.html (дата обращения: 20.01.2018).

6. 7 крупнейших страховых компаний России по данным за 9 месяцев 2016 г. [Электронный pecypc]. URL: http://moneymakerfactory.ru/spravochnik/krupnyie-strahovyie-kompanii-rossii/ (дата обращения: 20.01.2018); Крупнейшие страховые компании по итогам 2016 г. [Электронный ресурc]. URL: www.test.ppfinsurance.ru (дата обращения: 20.01.2018) ; Рейтинг крупнейших страховщиков [Электронный ресурc]. URL: http://vid1.rian.ru/ig/ratings/Insurance-042017.pdf (дата обращения: 20.01.2018) ; Рейтинг страховых компаний 2016 г. [Электронный ресypc]. URL: http://pfgfx.ru/straxovanie/rejting-straxovyx-kompanij-2016.html (дата обращения: 20.01.2018).

7. Бакулина М., Скворцова Я., Ващенко Т.В. Развитие форм взаимодействия банков и страховых компаний (банкострахование) // Актуальные проблемы авиации и космонавтики. 2012. № 8, т. 2. С. 218-219.

8. Pennacchi G. Deposit Insurance, Bank Regulation, and Financial System Risks // Journal of Monetary Economics. 2006. Vol. 53, no. 1. P. 1-30. https://doi.org/10.1016/j.jmoneco.2005.10.007.

9. Скворцова Н.В., Урмацких С.А. Рынок банкострахования в России: современное состояние, проблемы и новые правила его функционирования // Экономика и современный менеджмент: теория и практика : сб. ст. по материалам XXXV междунар. науч.-практ. конф. 2014. № 3 (35). C. 24-33.

10. Diamond D.W., Dybvig P.H. Banking Theory, Deposit Insurance, and Bank Regulation // The Journal of Business. 1986. Vol. 59, no. 1. P. 55-68.

11. Екимов А.В. Формы стратегического партнерства коммерческих банков и страховых компаний // Материалы XX научно-практической конференции молодых ученых, аспирантов и студентов Национального исследовательского Мордовского государственного университета им. Н.П. Огарева : в 3 ч. Ч. 3. Саранск, 2016. С. $293-297$; Макин М.В., Садыкова В.И. Состояние и перспективы развития банковского страхования в России [Электронный ресурс] // Политика, экономика и инновации. 2016. № 7 (9). URL: http://pei-journal.ru/index.php/PEII/article/view/186 (дата обращения: 13.02.2018)

12. Рынок банкострахования: перезагрузка [Электронный ресурc]. URL: https://raexpert.ru/researches/insurance/reboot (дата обращения: 20.01.2018) ; Страховые брокеры. Состояние дел и перспективы развития [Электронный ресурс]. URL: http://docplayer.ru/29649090-Strahovye-brokery-sostoyanie-del-i-perspektivy-razvitiya-g-moskva-strahovye-brokerysostoyanie-del-i-perspektivy-razvitiya.html (дата обращения: 20.01.2018).

13. Ахмедов Ф.Н., Алиев У.И. Развитие рынка банкострахования Российской Федерации в современных условиях // Финансы и кредит. 2013. № 4 (532). С. 68-69.

\section{References:}

Akhmedov, FN \& Aliev, UI 2013, 'Development of the bank insurance market of the Russian Federation in the modern context', Finansy $i$ kredit, no. 4 (532), pp. 68-69, (in Russian).

Bakulina, M, Skvortsova, Ya \& Vashchenko, TV 2012, 'Development of forms of interaction between banks and insurance companies (bank insurance)', Aktual'nyye problemy aviatsii i kosmonavtiki, no. 8, vol. 2, pp. 218-219, (in Russian).

Diamond, DW \& Dybvig, PH 1986, 'Banking Theory, Deposit Insurance, and Bank Regulation', The Journal of Business, vol. 59, no. 1, pp. 55-68. https://doi.org/10.1086/296314.

Ekimov, AV 2016, 'Forms of strategic partnership of commercial banks and insurance companies', Materialy XX nauchnoprakticheskoy konferentsii molodykh uchenykh, aspirantov i studentov Natsional'nogo issledovatel'skogo Mordovskogo gosudarstvennogo universiteta im. N.P. Ogareva, in 3 parts, part 3, Saransk, pp. 293-297, (in Russian).

Makin, MV \& Sadykova, VI 2016, 'The state and prospects of bank insurance development in Russia', Politika, ekonomika $i$ innovatsii, no. 7 (9), viewed 13 February 2018, <http://pei-journal.ru/index.php/PEIl/article/view/186>, (in Russian).

Pennacchi, G 2006, 'Deposit Insurance, Bank Regulation, and Financial System Risks', Journal of Monetary Economics, vol. 53, no. 1, pp. 1-30. https://doi.org/10.1016/j.jmoneco.2005.10.007.

Skvortsova, NV \& Urmatskikh, SA 2014, 'Bank insurance market in Russia: the current state, problems and new rules of its functioning', Ekonomika i sovremennyy menedzhment: teoriya i praktika: sb. st. po materialam XXXV mezhdunar. nauch. -prakt. konf, no. 3 (35), pp. 24-33, (in Russian).

Zagirova, NR \& Aleksandrova, NG 2016, 'Analysis of the Russian insurance market for 2014-2016 and the prospects for its development', Fundamental'nyye issledovaniya, no. 11, part 5, pp. 1006-1010, viewed 13 February 2018, <http://fundamentalresearch.ru/ru/article/view?id=41292>, (in Russian). 